\title{
RECONSTRUCTING SURFACE TRIANGULATIONS BY THEIR INTERSECTION MATRICES ${ }^{1}$
}

\author{
Jorge L. Arocha, Javier Bracho \\ NATAlia García-Colín \\ AND \\ ISABEL HUBARD \\ Instituto de Matemáticas \\ Universidad Nacional Autónoma de México \\ CU, México D.F. 04510 \\ e-mail: arocha@matem.unam.mx \\ jbracho@matem.unam.mx \\ garcia@matem.unam.mx \\ hubard@matem.unam.mx
}

\begin{abstract}
The intersection matrix of a simplicial complex has entries equal to the rank of the intersecction of its facets. We prove that this matrix is enough to define up to isomorphism a triangulation of a surface.
\end{abstract}

Keywords: triangulated surface, isomorphism, intersection matrix.

2010 Mathematics Subject Classification: 05C10, 57M15.

\section{REFERENCES}

[1] R. Blind and P. Mani-Levitska, Puzzles and polytope isomorphisms, Aequationes Math. 34 (1987) 287-297. doi:10.1007/BF01830678

[2] G. Kalai, A simple way to tell a simple polytope from its graph, J. Combin. Theory Ser. A 49 (1988) 381-383. doi:10.1016/0097-3165(88)90064-7

\footnotetext{
${ }^{1}$ Research was partially supported by grants CONACyT 166951 and DGAPA IN112511.
} 
[3] B. Mohar and A. Vodopivec, On polyhedral embeddings of cubic graphs, Combin. Probab. Comput. 15 (2006) 877-893. doi:10.1017/S0963548306007607

[4] G.M. Ziegler, Lectures on Polytopes, Graduate Texts in Mathematics, Springer, (1995).

doi:10.1007/978-1-4613-8431-1

Received 8 January 2014

Revised 26 September 2014

Accepted 22 October 2014 